\title{
The Lean Design of Manufacturing Process'
}

\section{Summary}

This article is intended to using of Six Sigma methodology. A break trough strategy to significantly improve customer satisfaction and shareholder value by reducing variability in every aspects of business. It enhances the ability to delivery customer satisfaction and cost improvement results faster - within months from the start, and sustains the rate of improvement on-going. One of the most powerful ways to improve business performance is combining business process management (BPM) strategies with Six Sigma strategies. BPM strategies emphasize process improvements and automation to drive performance, while Six Sigma uses statistical analysis to drive quality improvements. The two strategies are not mutually exclusive, however, and some savvy companies have discovered that combining BPM and Six Sigma can create dramatic results. Six Sigma methodology teaches and deploys hard skills and business practices emphasizing.

\section{Introduction}

The basic concepts of Six Sigma were developed at Motorola in the 1980's as they worked to improve the quality of their products and services. They have been refined and improved over the years by many successful companies. By implementing a systematic, rigorous routine, they were able to improve their services or products and increase customer satisfaction, thus increasing profits.

Six Sigma approaches business processes from a highly analytical point of view. It incorporates five levels of activity:

* Dr inż., Department of Economics and Management of Chemical and Food Industry, Institute of Chemical Technology Prague, Czechy

${ }^{1}$ This article is published as the part of research intention MSM 6046137306. 
- Philosophy - the enterprise-wide embrace of defect reduction by making decisions based on hard data and customer focus.

- Focus on the Customer - meet or exceed their requirements/expectations.

- Metrics - statistical focus to make process outcomes 99,9997\% defect free, otherwise expressed as 3.4 defects per million opportunities.

- Methodology - structured approach to solving problems that uses specific tools and process mapping to achieve the metric goal.

- Process based - the defects or errors introduced into products or services are based upon deficiencies in the processes.

In short, Six Sigma allows an organization to reduce the variability in its products and services so that waste is reduced, efficiency is improved, and customer satisfaction is dramatically increased. Business problems are solved through rigorous application of data collection and analysis tools. The training that Six Sigma users receive is quite intensive, progressing through several increasingly sophisticated levels based on experience and accomplishment. Professional Six Sigma consultants and practitioners usually work to become certified at the various levels, increasing their ability to help guide development and implementation of Six Sigma methodology.

\section{Six Sigma phases}

The methodology of Six Sigma is the key to its success. An organization follows a five step progression (DMAIC) (BBd! Nie mo|na odnalez zródBa odsyBacza.) that uses information and statistical analysis to address the achievement of operational goals. There are some differences in the five steps depending on whether they are used to improve an existing process or design a new process. The end goal, though, is always to achieve the standard metric of $99.9997 \%$ defect free performance.

Fig. 1. The five phases of Six Sigma

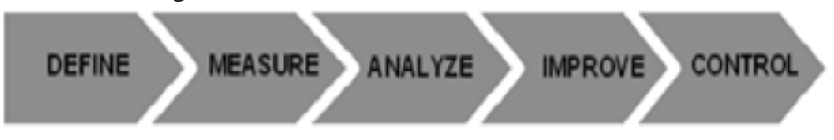

1. Define. The Define phase is concerned with the definition of project goals and boundaries, and the identification of issues that need to be addressed to achieve the higher (better) sigma level.

2. Measure. The goal of the Measure phase of the Six Sigma strategy is to gather information about the current situation, to obtain baseline data on current process performance, and to identify problem areas.

3. Analyze. The goal of the Analyze phase of the Six Sigma quality effort is to identify the root cause(s) of quality problems, and to confirm those causes using the appropriate data analysis tools.

4. Improve. The goal of the Improve phase is to implement solutions that address the problems (root causes) identified during the previous (Analyze) phase. 
5. Control. The goal of the Control phase is to evaluate and monitor the results of the previous phase (Improve).

Basically identify an area where there is a process problem, measure it, work out why there is a problem and then fix it.

\section{Project selection}

Proper project selection is one of the most critical factors influencing the outcome of consumer driven Six Sigma projects.

Selecting a projects that is too large will cause valuable time to be lost during the define phase as project teams struggle to scope their projects and develop "Problem statements" that can be addressed using Six Sigma. A fundamental formula used in Six Sigma is that "Y" is a function of " $\mathrm{X}$ ":

$$
Y=f(X)
$$

In mathematical terminology, " $Y$ " is the dependent variable while " $\mathrm{X}$ " is the independent variable. Expressed in another way, " $Y$ " is an output resulting from number of inputs or " $\mathrm{X}$ ". The typical diagram used to communicate this concept in consumer driven Six Sigma is as follows:

$$
Y=X_{1} X_{2} X_{3} X_{4}
$$

Building on this concept, it canbe said that every " $\mathrm{X}$ " is correlated to " $\mathrm{Y}$ " at some deeper level in the process. The diagram for this cascading relationship is as follows:

$$
\begin{aligned}
& Y=X_{1} X_{2} X_{3} X_{4} \\
& \Downarrow \\
& Y=X_{1} X_{2} X_{3} X_{4} \\
& \Downarrow \\
& Y=X_{1} X_{2} X_{3} X_{4}
\end{aligned}
$$

This method of "drilling down" to the specific issues is the fundamental technique for both project selection and project scoping. Those trained in Six Sigma techniques are often heard describing issues in terms of the "Xs" and Ys". On the Fig. 2 it has at one's disposal the example. Y/X diagram on Fig. 2 illustrates how the project selection process is used to narrow high-level outcomes (big "Ys") down to specific actionable issues (project level "Xs"). ${ }^{2}$ Project selection is most often performed at the project champion level and is critical that black belts and project teams have specific issues to address. Without clear direction, projects frequently stall in the define and measure phases as it

${ }^{2}$ Delivery conditions and delivery timing will be used throughout this part as example to explain Six Sigma tools and techniques. 
becomes difficult to pinpoint what data to collect and how to make use of it. To ensure that projects are appropriately selected, the champion can apply the project selection checklist appearing.

\section{Define phase}

The purpose of the define phase is to further refine the Six Sigma project team's understanding of the problem to be addressed. In addition, the project team will use the define phase to get organized, determine roles and responsibilities, establish goals and milestones and review process steps. At the completion of the define phase, the project team will have:

- Defined the problem with a problem statement ${ }^{3}$,

- Specifically identified the process or product's customer,

- Defined CTQs (Critical to Quality characteristics) from the customer's viewpoint,

- Scoped the project,

- Produced a refined problem statement.

Identify customer - in this step, the project team will determine who is directly impacted by the problem and what costs can be associated whit that impact. ${ }^{4}$ Once a customer is identified, the project team will need to determine what is important to that customer from the customer's point of view. In Six Sigma terminology this process is referred characteristic (CTQs). Identification of CTQs ascertains how the particular characteristics appear when meeting customer expectations. After CTQs are identified, the project team must develop operational definitions foe each CTQ. Effective operational definitions:

- Accurately describe the critical - to-quality characteristic,

- Specifically annotate what is considered meeting the customer expectation,

- Are written to ensure consistent interpretation and measurement by multiple people.

Commonly used methods of identifying CTQs include, but are not limited, to focus group, surveys or interviews. Outputs of this step are CTQs, operational definitions and parameters for measuring too. When project team members the scope project do, must above all further specify project issues, develop a refined problem statement and brainstorm suspected sources of variation. Similar to the process used in project selection, team members must strive to reduce the scope of their project to a level that ensures the problem is within the team's area of control that ensures data can be collected to show both the current and improved states. A refined problem statement is a highly defined description of the problem. Beginning with the general problem statement and applying what has been learned through further scoping. Project team writes and refined problem

\footnotetext{
${ }^{3}$ Upon completion of this step, the team should have a problem statement that - describes the problem based on available data, does not include assumptions regarding possible cause or solutions, identifies key metrics.

${ }^{4}$ During the identify customer step, the project team attempts to target a specific se of customers. Correcting the problem for this set of customers generates the largest benefit and improvement can usually be expanded to larger groups of customers.
} 
Fig. 2. Example for using Six Sigma methodology

\begin{tabular}{|c|c|c|}
\hline \multirow[t]{2}{*}{$\begin{array}{c}Y=X_{1} X_{2} X_{3} X_{4} \\
\Downarrow \\
\Downarrow \\
Y=X_{1} X_{2} X_{3} X_{4}\end{array}$} & $\Leftarrow \Leftarrow$ & $\begin{array}{l}\text { The taste of a glass of lemonade (the "Y") is influenced by } \\
\text { a number of factors including: } \\
\text { - Type of lemon ingredient (an "X") } \\
\text { - Amount of sugar added (an "X") } \\
\text { - Type of water used (an "X") } \\
\left.\text { - Amount of ice added (an" } \mathrm{X}^{\prime \prime}\right)\end{array}$ \\
\hline & $\Leftarrow \Leftarrow$ & $\begin{array}{l}\text { Extending the example, if the lemon ingredient factor was } \\
\text { to be examined further, the " } X \text { " variables might include: } \\
\text { - Fresh squeezed lemon (a potential "X") } \\
\text { - Liquid concentrate (a potential " } X^{\prime \prime} \text { ) } \\
\left.\text { - Frozen concentrate (a potential " } X^{\prime \prime}\right) \\
\text { - Powdered lemon flavouring (a potential "X") }\end{array}$ \\
\hline
\end{tabular}

statement that describes the problem in narrow terms, indicates a level where the team will begin its work and identifies the extent of the problem and how it measured. Effective tools to scope projects include cause-and-effect diagram (fishbone), cause-and-effect matrix, FMEA and $\mathrm{Y} / \mathrm{X}$ diagram.

\section{Measure phase}

The purpose of the measure phase is to establish techniques for collecting data about current performance that highlights project opportunities and provides a structure for monitoring subsequent improvements. Upon completing the measure phase, project team will have a:

- Plan for collecting data that specifies the data type and collection technique,

- Validated measurement system that ensures accuracy and consistency,

- Sufficient sample of data for analysis,

- Set of preliminary analysis results that provides project direction,

- Baseline measurement of current performance.

The key concepts of measure phase consist on sound data collection plan, identification of key process input variables (KPIV), variation displayed using pareto charts, histogram and run charts. The most important step of the measure phase is a wellprepared data collection plan. It is critical that the project team spends the appropriate amount of time developing the data collection plan. Investing time in developing the plan can help avoid collection errors that may result in data corruption or the collection of data that is not relevant to the project. Conversely, even the well-developed plan may require revisions as the project team becomes enlightened regarding. Process details. ${ }^{5}$ In the next step must prepare perform measurement system analysis. It is important to ensure the

${ }^{5}$ The project team should make certain that ample consideration has been given to the various factors (Xs) that might be causing variation in the process. It is very important that, where applicable, data be sub grouped to determine variation between the subgroups. For example if the Xs were typos observed in a document, the project team might subgroup the data as follows: person-to-person, office-to-office, shift-to shift, week-to-week, etc. 
information collected is a true representation of what is occurring in the process. At the conclusion of the measurement system analysis, the project team should know:

- Whether the measurement system is "capable" of gathering data that accurately reflect variation in the process,

- Whether there is measurement error, how big it is and method of accounting for it,

- What confidence level can be attached to the measurement collected,

- Whether or not measurement increments are small enough to show error,

- Whether the measurement system will be stable over time.

The project team member must conduct data collection, perform graphical analysis and conduct base analysis too.

\section{Analyze and improve phase}

As an outcome of the measure phase, the project team should be narrowing its focus on distinct groups of project issues and opportunities. The analyze phase allows the project team to further target improvement opportunities by taking a closer at the data. Upon completion of the analyze phase, project team members should be able to answer - what was the approach to analyzing, what was the improvement opportunity, what are the causes contributing to the improvement opportunity, how was the data analyzed to identify sources of variation or did analysis result in any changes to the problem statement or scope? The BBd! Nie mo|na odnalez zródBa odsyBacza. shows mutual relations between single activities of analyze and improve phase and shows used tools too.

To begin the analyze phase, the project team needs to confirm the type of data that has been collected, either attribute or variable. Based on the data type, the project team will use one of two sets of analysis tools:

- Attribute data tools (attribute data reflecting one of two conditions such as Yes/No; Defect/No defect; Accurate/Inaccurate):

- Variable data tools (test for level of variation within a data sample). For example F-Test (tests and compares two data sets for variance; assumes a random sample of normal data; Null hypothesis (Ho) = both data samples have the same degree of variance; P-Value greater than $0,05=$ accept the null hypothesis; P-Value less then $0,05=$ reject null hypothesis.) Maybe is possible ANOVA test (analysis of variation homogeneity of variance) - tests and compares there or more data samples for variance; Bartlett's requires normal data, levee's does not require normal data; Null hypothesis $(\mathrm{Ho})=$ all data samples have the same degree of variance; P-Value greater than $0,05=$ accept the null hypothesis; P-Value less then $0,05=$ reject null hypothesis.

As an outcome of the analyze phase, project team members should have a strong understanding of the factors impacting their project, including - key process input variables (KPIV) - also the vital few "Xs" that impact the "Y". Including sources of variation - where the greatest degree of variation exists. The purpose of the improve phase is to generate ideas, design, pilot and implement improvements and validate improvements. The team members can use next key concepts: brainstorming, "should 
be" process map, FMEA, etc. at the conclusion of the improve phase, the project team will have identified alternative improvement, implemented the best alternative for improving the process, validated the improvement and prepared for transition to the control phase. ${ }^{6}$

\section{Control phase}

The purpose of the control phase is to institutionalize process/product improvements and monitor ongoing performance. Following the improve phase, the project team needs to transition control of the process back to the process owner. To facilitate a smooth transition and ensure the project team's work sticks, a detailed control plan will be developed. The objective of the control plan is to document all pertinent information regarding - who is responsible for monitoring and controlling the process, what is being measured, performance parameters, corrective measures. Key components of the control plan include mistake proofing, long-term MSA plan, control chart - statistical process control (SPC), reaction plan, update standard operating procedures. Upon completion of

Fig. 1. Analyze and improve phase

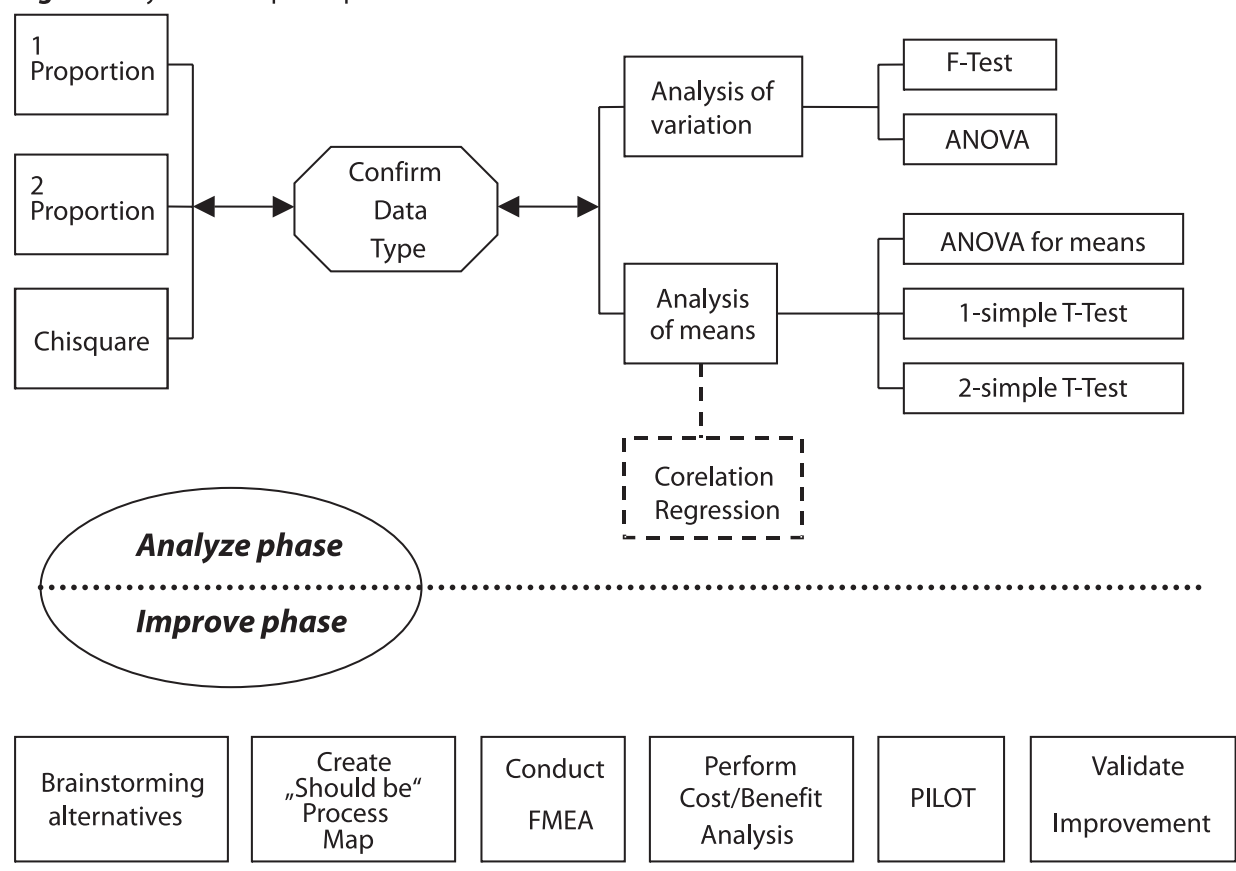

${ }^{6}$ Design of experiments (DOE) is an effective tool that can be used in both the analyse and improve phase of the DMAIC process. However, DOE can be a difficult tool to use outsider of a manufacturing environment where small adjustment can be made to input factors and output can be monitored in real time. 
the control phase, the process owner will understand performance expectations, how to measure and monitor Xs to ensure performance of the Y, and what corrective actions should be executed if measurements drop below desired levels. Likewise, after completion of the control phase, the project team members disband while the black belt begins the next consumer driven Six Sigma project with a new team.

\section{Conclusion}

Variable data is sometimes more desirable than attribute data to use, because it requires smaller sample sizes. However, some projects appear to provide only attribute data (damaged units, number of incorrect invoices). The design of experiment (DOE) is an extremely valuable tool not only in identifying key input variables causing variation but also in setting the operating tolerances (precise levels) of the key input. DOE works well in manufacturing processes where equipment can be adjusted incrementally and output can be analyzed over time. With this basic understanding of BPM and Six Sigma in mind, it is easy to see how powerful it can be to combine the two practices. Their strengths complement each other and create a synergy that instils the entire operation with a focus on quality and performance. The strength of BPM lies in its ability to automate processes and workflow through modelling and examination of inputs, outputs and performance. It is not as strong, however, in its ability to analyze data associated with very difficult or multifaceted problems. Six Sigma fills this gap by providing the statistical analysis needed to deal with complex problems.

Fig. 4. Combiming BPM and Six Sigma

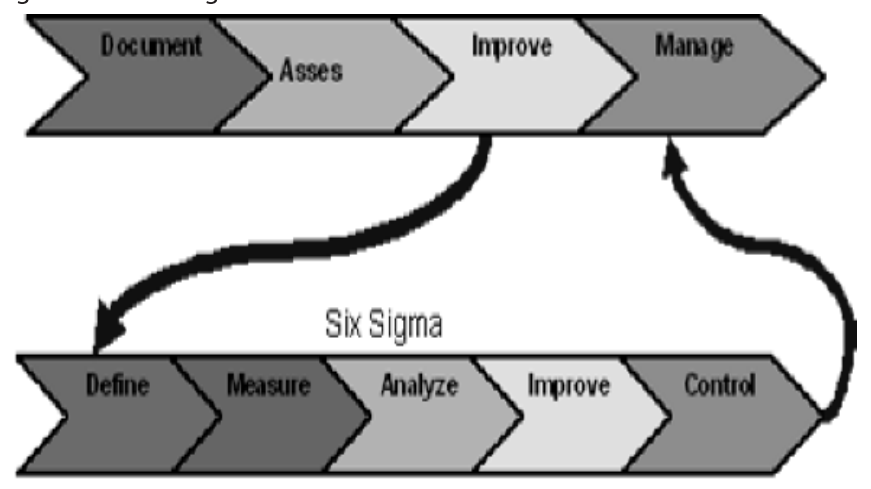

The strength of Six Sigma lies in its rigorous approach to data collection and analysis. Through this methodology it can identify even the smallest opportunities for process improvement, maximizing an organization's ability to institute necessary changes. It is not as strong, however, in its ability to monitor process improvements and ensure they are applied across the board. BPM fills this gap by providing tools to automate process improvements and connect those improvements across the entire organization. Both BPM 
and Six Sigma represent significant commitments on the part of a business or organization, and they take time to implement thoroughly. Tremendous organizational change is often required, leading most companies to start with a single department or pilot project and expand their use over a multi-year period. It is well worth the time and effort, though, to generate the substantial business improvements that are typical with BPM and Six Sigma.

\section{References}

Balatka S., Inženýrksá statistika pro ekonomy, VŠCHT, Praha 2000.

Barlow R., Statistics, John Wiley and Sons, Chichester 1999.

George M., Rowlands D., Kastle B., What is Lean Six Sigma. Manual, Six Sigma Academy, 2002.

Gitlow H., Project Six Sigma, Studies, University of Miami, Miami 2004.

Tošenovský J., Manuál Six Sigma. Handbook for Managers, VŠB, Ostrava 2003.

\section{Odchudzanie projektów procesów produkcyjnych}

\section{Streszczenie}

Artykut przedstawia możliwości wykorzystania metody Six Sigma w zawężaniu skali procesów produkcyjnych. Metoda ta pozwala przede wszystkim na zredukowanie wielu powtarzajacych się czynności celem osiagnięcia wyższych korzyści w zakresie sprzedaży i tworzenia wartości przedsiębiorstwa. Najbardziej wartościowym dla przedsiębiorstw produkcyjnych jest powiqzanie zarzadzania procesami ze strategia Six Sigma. Metoda ta wymaga wtedy szerszego stosowania narzędzi statystycznych w projektowaniu $i$ kontroli procesów produkcyjnych. Choć obie metody nie sq nowe, to w ostatnim czasie przedsiebiorstwa odkryly ich taczna przydatność w odchudzaniu projektów nowych procesów wytwórczych. 